\title{
Aerocapture Performance Analysis for a Neptune-Triton Exploration Mission
}

\author{
Brett R. Starr \\ NASA Langley Research Center, Hampton, Virginia, 23681-2199 \\ Carlos H. Westhelle ${ }^{\dagger}$ and James P. Masciarelli ${ }^{\dagger}$ \\ NASA Johnson Space Flight Center, Houston, Texas, 77058
}

\begin{abstract}
A systems analysis has been conducted for a Neptune-Triton Exploration Mission in which aerocapture is used to capture a spacecraft at Neptune. Aerocapture uses aerodynamic drag instead of propulsion to decelerate from the interplanetary approach trajectory to a captured orbit during a single pass through the atmosphere. After capture, propulsion is used to move the spacecraft from the initial captured orbit to the desired science orbit. A preliminary assessment identified that a spacecraft with a lift to drag ratio of 0.8 was required for aerocapture. Performance analyses of the $0.8 \mathrm{~L} / \mathrm{D}$ vehicle were performed using a high fidelity flight simulation within a Monte Carlo executive to determine mission success statistics. The simulation was the Program to Optimize Simulated Trajectories (POST) modified to include Neptune specific atmospheric and planet models, spacecraft aerodynamic characteristics, and interplanetary trajectory models. To these were added autonomous guidance and pseudo flight controller models. The Monte Carlo analyses incorporated approach trajectory delivery errors, aerodynamic characteristics uncertainties, and atmospheric density variations. Monte Carlo analyses were performed for a reference set of uncertainties and sets of uncertainties modified to produce increased and reduced atmospheric variability. For the reference uncertainties, the $0.8 \mathrm{~L} / \mathrm{D}$ flatbottom ellipsled vehicle achieves $100 \%$ successful capture and has a 99.87 probability of attaining the science orbit with a 360 $\mathrm{m} / \mathrm{s} \Delta \mathrm{V}$ budget for apoapsis and periapsis adjustment. Monte Carlo analyses were also performed for a guidance system that modulates both bank angle and angle of attack with the reference set of uncertainties. An alpha and bank modulation guidance system reduces the 99.87 percentile $\Delta V 173 \mathrm{~m} / \mathrm{s}(48 \%)$ to $187 \mathrm{~m} / \mathrm{s}$ for the reference set of uncertainties.
\end{abstract}

*Aerospace Engineer, Vehicle Analysis Branch, 100 NASA Rd/365, Member.

Aerospace Engineer, Advanced Mission Design Branch, 2101 NASA Rd/mail code EG5, Member

$¥$ Currently Principal Engineer at Ball Aerospace, 1600 Commerce St/Mail Stop T-1, Boulder CO., Senior Member 


\section{Nomenclature}

$\begin{array}{ll}\mathrm{AU} & =\text { Astronomical Unit } \\ \mathrm{C}_{\mathrm{A}} & =\text { Aerodynamic axial force coefficient } \\ \mathrm{C}_{\mathrm{N}} & =\text { Aerodynamic normal force coefficient } \\ \mathrm{C} . \mathrm{G} . & =\text { Center of Gravity } \\ \mathrm{DOF} & =\text { degree of freedom } \\ \text { GRAM } & =\text { Global Reference Atmospheric Model } \\ \mathrm{HYPAS} & =\text { Hybrid Predictor-corrector Aerocapture Scheme } \\ \text { JPL } & =\text { Jet Propulsion Laboratory } \\ \text { L/D } & =\text { Lift to drag ratio } \\ \text { LAURA } & =\text { Langley Aerodynamic Upwind Relaxation Algorithm } \\ \text { POST } & =\text { Program to Optimize Simulated Trajectories } \\ \mathrm{SEP} & =\text { Solar electric propulsion } \\ \mathrm{TPS} & =\text { Thermal protection system } \\ \Delta \mathrm{V} & =\text { Velocity addition } \\ \sigma & =\text { Standard deviation }\end{array}$

\section{Background}

\section{A. Neptune-Triton Exploration Reference Mission}

The reference Neptune-Triton exploration mission was designed to provide Cassini and Galileo level exploration of the Neptune system. ${ }^{2}$ The reference mission has a science orbiter to explore the Neptune-Triton system and two probes that enter Neptune's atmosphere 60 degrees apart in latitude. The science orbiter is placed in orbit about Neptune using an aerocapture maneuver described below. The science orbit can range between $3896 \mathrm{x} 355000 \mathrm{~km}$ and $3896 \times 500000 \mathrm{~km}$. The aerocapture maneuver would be followed by propulsive maneuvers to place the spacecraft in a phasing orbit such that subsequent maneuvers would establish an orbit that would encounter Triton at regular intervals. Triton is then used as a tour engine to vary the orbit's inclination and line of apsides similar to Cassini's use of Titan. The reference orbiter would measure atmospheric, magnetic, and gravity characteristics and perform global imaging of both Triton and Neptune.

Launch dates studied for the Neptune-Triton Exploration mission range from 2016 to 2019. A February 21, 2017 launch date was chosen for this study with launch on a Delta IV 4050 Heavy launch vehicle inside a $5 \mathrm{~m}$ fairing and a transit time of 10.25 years $^{3}$. The launch spacecraft configuration consists of the orbiter, two entry probes, and a solar electric propulsion module. Five months prior to reaching Neptune, the two probes are released sequentially such that both probes' missions are completed before the orbiter reaches Neptune. ${ }^{4}$ Four and a half months prior to reaching Neptune, a trajectory deflection maneuver is performed to target the entry interface point for aerocapture. Thirty minutes prior to entry interface the SEP is jettisoned. After atmospheric entry, the spacecraft executes the aerocapture maneuver described below to place the orbiter in the exploration orbit and begin a two or more year science mission.

1. Aerocapture Overview

Aerocapture is a form of aeroassist used to insert a spacecraft into a desired orbit at targets with an atmosphere. Aerocapture uses aerodynamic forces to dissipate the hyperbolic approach energy to an energy level needed to reach a target apoapsis after making a single pass through the atmosphere. An active guidance system must be used during the aeropass to compensate for uncertainties in entry flight path angles, atmospheric density profiles, and aerodynamics. After exiting the atmosphere, propulsive maneuvers are required to change the spacecraft's exit orbital elements to that of the desired phasing orbit. These maneuvers include a periapsis raise and any needed adjustments in apoapsis, inclination, and longitude of ascending node. The aerocapture maneuver is illustrated in Fig. 1. After the proper phasing with Triton is achieved, additional propulsive maneuvers are performed to provide the desired Triton encounter strategy. The $\Delta \mathrm{V}$ required for the initial periapsis raise and assumed apoapsis for phasing was used as a performance metric in this study. 


\section{Simulation of Aerocapture Orbit Insertion}

A high fidelity 3 DOF simulation of the aerocapture maneuver used to insert the spacecraft into its phasing orbit was developed in the program to optimize simulated trajectories, POST $^{9}$. The aerocapture trajectory was simulated from the navigation delivery point, nominally 60 seconds prior to atmospheric interface, to atmospheric exit. The simulation determined the spacecraft's trajectory through Neptune's atmosphere and tracked key design parameters such as heat loads, deceleration loads, and $\Delta \mathrm{V}$ required for the periapsis raise and apoapsis adjustments. The simulation was run in a Monte Carlo using uncertainties in the delivery point, spacecraft aerodynamics, and atmospheric density profiles to provide statistical data for the design parameters.

The simulation incorporated delivered states, aerodynamics, guidance, and control models specifically developed for the aeroshell and a model of Neptune's atmosphere as shown in Fig. 2. A brief description of each model follows.

\section{A. Atmosphere}

An engineering type model of Neptune's atmosphere developed at Marshall Space Flight Center provided atmospheric state properties and composition. ${ }^{6}$ The model, named Neptune-GRAM, is a global reference atmospheric model. Neptune-GRAM's state and composition properties were based on data from the Voyager flyby and stellar occultations. ${ }^{6}$ Refer to reference 6 for a complete description of Neptune-GRAM.

Neptune's state property versus altitude relationships vary with latitude, season and time of day. These variations are represented in Neptune-GRAM by a parameter termed Fminmax. Fminmax ranges from -1 to +1 and is used to select a state property versus altitude profile for a particular latitude, season and time of day. Figure 3 shows the maximum range of density versus altitude profiles.

In the aerocapture simulation, the density versus altitude relationship was made to vary with latitude by making Fminmax a cosine function of latitude and was made to vary with season by adding a constant bias term, Fbias, to the latitudinal variation as shown in Eq. 1.

$$
\text { Fminmax }=0.44 * \cos (4.0 * \text { latitude })+\text { Fbias }
$$

The range of Fbias was set to -0.56 to +0.56 so that Fminmax stayed within its -1 to +1 bounds. Figure 4 shows the variation of Fminmax with latitude.

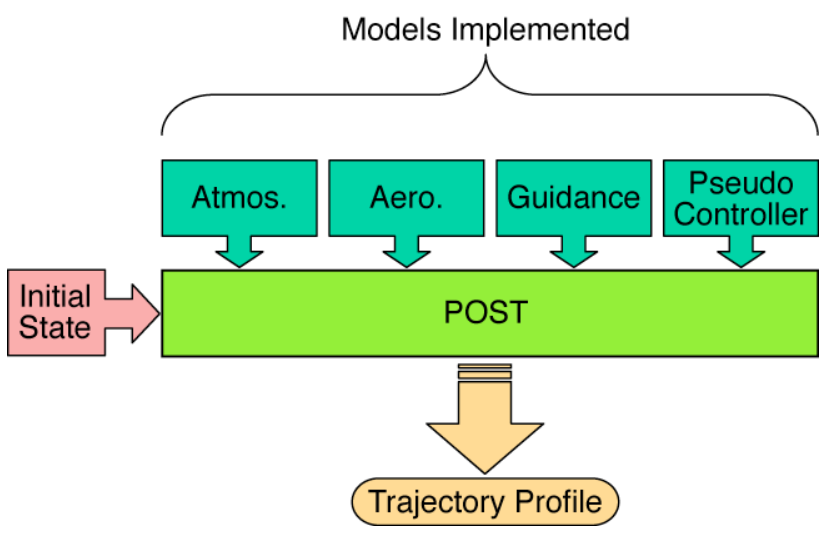

Figure 2. Models incorporated into POST simulation of Neptune aerocapture.

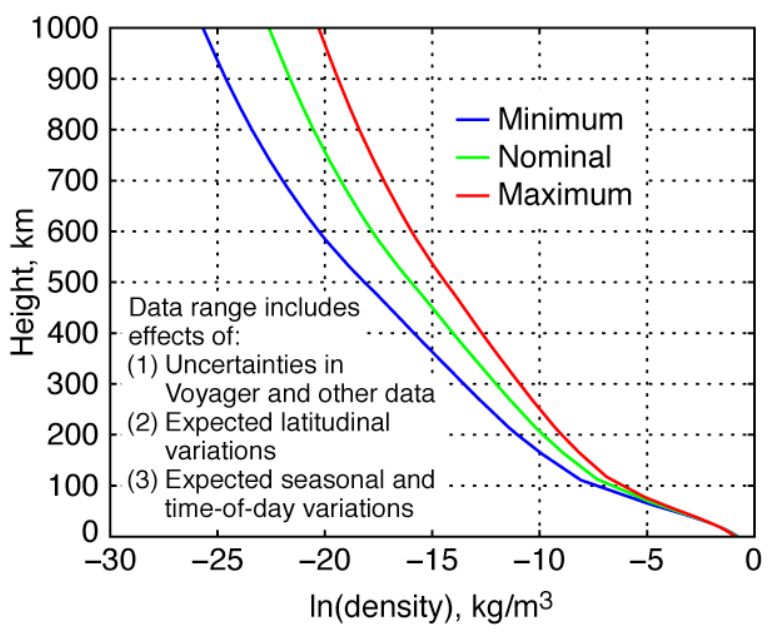

Figure 3. Neptune atmosphere model density profiles. 
Neptune-GRAM also superimposed high frequency perturbations onto the nominal atmospheric data to represent random variations in atmospheric properties. The magnitude of the perturbations can be scaled using the Neptune-GRAM parameter rpscale. A random perturbation seed value was used to generate randomly perturbed density values. Figure 5 shows randomly perturbed density versus altitude profiles for Fminmax $=-1,0$ and +1 .

\section{B. Aerodynamics}

A high fidelity aerodynamics model of the flat bottom ellipsled aeroshell was developed and incorporated into the simulation as an aerodynamic coefficient database. The database supplied axial and normal force coefficients as a function of angle of attack in the hypersonic flight regime. ${ }^{7}$ The aerodynamic force coefficients were considered constant throughout the aeropass. Refer to reference 7 for more information regarding aerodynamics. The aeroshell geometry is shown in Fig. 6.

\section{Navigation}

The Neptune-Triton Exploration Mission navigation model was provided by JPL. The navigation model determined vehicle entry states about a nominal $-12.82^{\circ}$ entry flight path angle and $29.0 \mathrm{~km} / \mathrm{s}$ entry velocity. The modeled navigation system delivered the spacecraft to atmospheric interface with a $3 \sigma$ dispersion of $\pm 0.51^{\circ}$ about the nominal entry flight path angle ${ }^{5}$. Refer to reference 5 for a complete description of the navigation model. Table 1 summarizes the navigation data used in the simulation.

Table 1. Navigation Data

\begin{tabular}{ccc}
\hline \hline $\begin{array}{c}\text { Entry } \\
\text { Velocity, km/s }\end{array}$ & $\begin{array}{c}\text { Entry Flight Path } \\
\text { Angle, deg }\end{array}$ & $\begin{array}{c}\text { Entry FPA } \\
\text { Uncertainty, deg }\end{array}$ \\
\hline 29.0 & -12.818 & \pm 0.5108 \\
\hline \hline
\end{tabular}

\section{Guidance}

The Hybrid Predictor-corrector Aerocapture Scheme (HYPAS) aerocapture guidance algorithm developed at Johnson Space Center provided autonomous guidance for the simulation. ${ }^{8}$ The HYPAS algorithm is an analytical control algorithm based on drag acceleration and altitude rate error for an aeropass through an exponential atmosphere.

In this study, two attitude control schemes were used by HYPAS. In the first, attitude control was limited to bank angle modulation. Bank angle controlled the rate of descent/ascent and effected drag through changes in atmospheric density. In this study, bank angle modulation was defined as the baseline guidance model. In the second attitude control scheme, attitude control included both angle of attack and bank angle modulation. Angle of attack modulation was

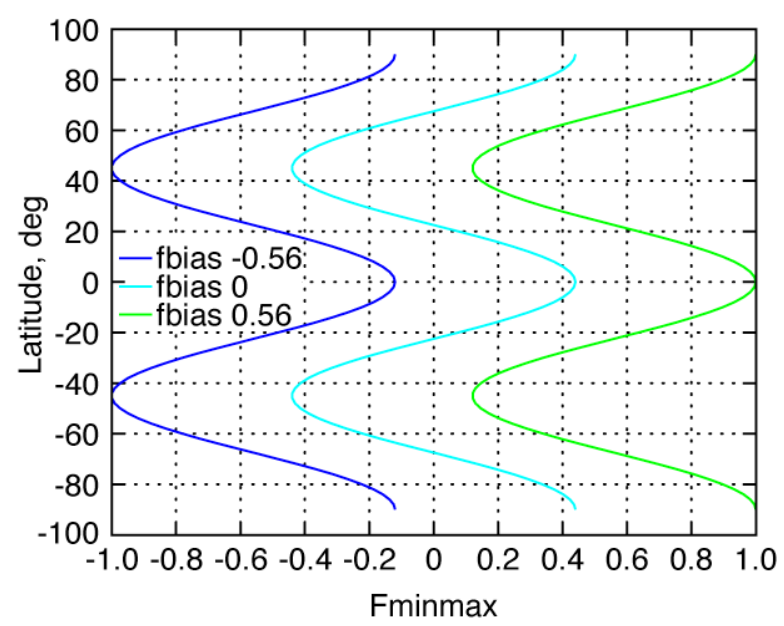

Figure 4. Latitudinal Variation of Fminmax.

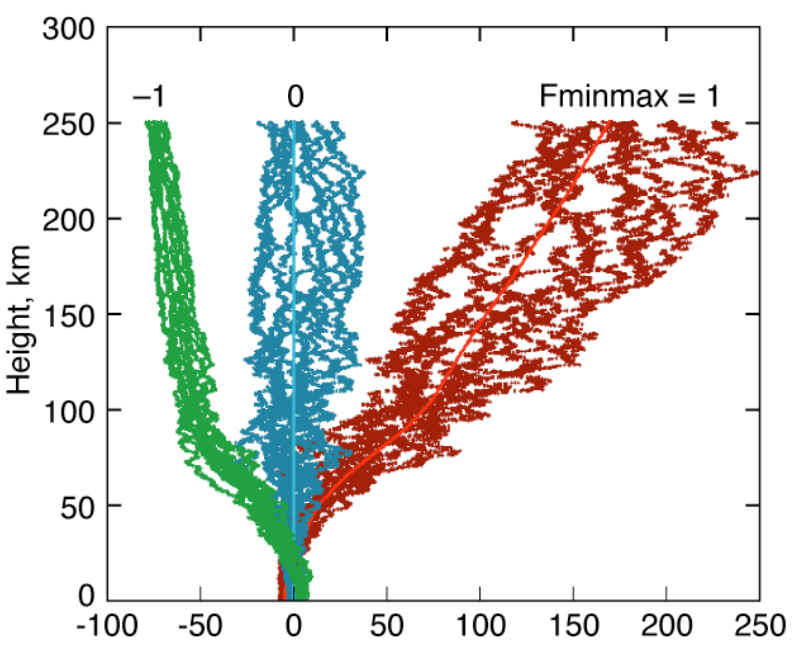

Perturbed Density (percent from Neptune Average)

Figure 5. Sample Neptune-GRAM Monte-Carlo density output.

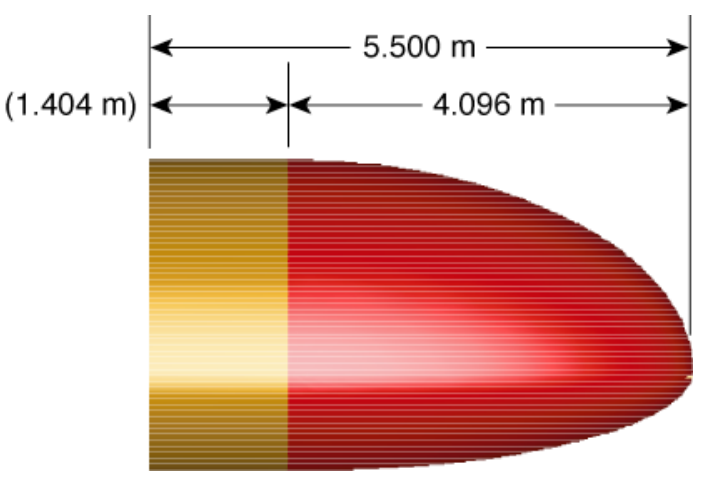

Figure 6. Aeroshell geometry. 
used first to modulate the L/D and ballistic coefficient to meet the desired vertical L/D or exit velocity. If changes in ballistic coefficient were not sufficient to meet the targets then bank angle modulation was used to further effect drag. As the required L/D and drag changed due to high frequency density perturbations, angle of attack modulation was used to drive the bank angle to $90^{\circ}$. In this study, the combined bank and angle of attack modulation was defined as the alpha modulated guidance model. Both the baseline and advanced guidance models used roll reversals to maintain the wedge angle between the exit orbit and Triton's orbit to within $1^{\circ}$. Refer to reference 8 for complete descriptions of the bank modulated and alpha modulated guidance models.

\section{E. Control}

A 3-DOF Pseudo controller developed at Langley Research Center was used to approximate the attitude dynamics of a 6 DOF system. The controller analytically calculated the time and angular travel required to reach the guidance commanded attitude. Once calculated, the controller ramped bank angle and/or angle of attack to the commanded value at a user specified maximum acceleration until the attitude rate reached a user specified maximum. The maximum acceleration and rates are defined such that the 3-DOF response is a good approximation of the 6-DOF system. This approach has provided good agreement with 6-DOF systems in previous simulations. Figure 7 shows the bank response to a bank command for the 3-DOF controller.

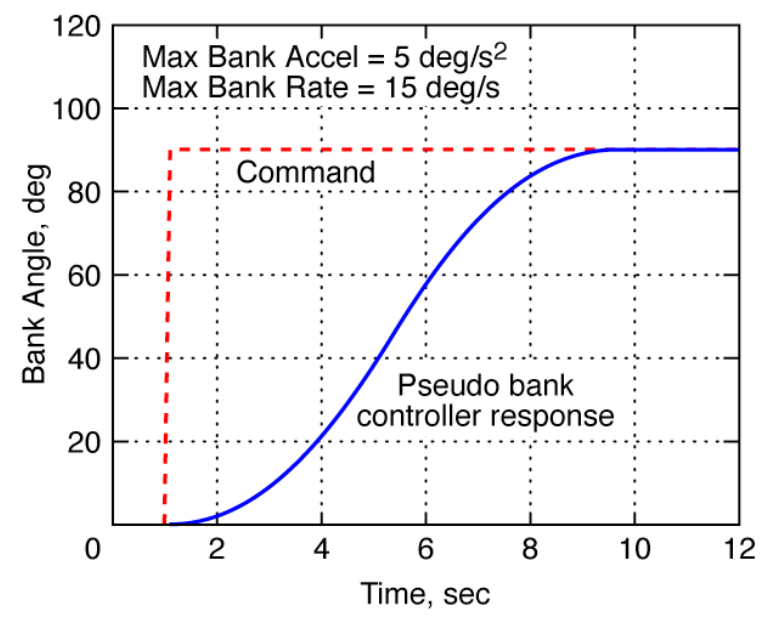

Figure 7. Bank Response of 3-DOF Bank Controller

\section{Monte Carlo Analysis}

The vehicle performance was quantified by statistical data from Monte Carlo Analyses. The analyses consisted of 2000 individual Neptune aerocapture simulations with random perturbations in arrival states, vehicle aerodynamics and Neptune's atmosphere. A Monte Carlo executive script created simulation input files with generated perturbations and coordinated simultaneous execution of the simulations on multiple processors across multiple computers. Various post processing scripts were used to determine the statistical parameters for the 2000 simulations in each Monte Carlo analysis and to generate plots.

The Monte Carlo analyses consisted of a reference case and three sensitivity case studies. In the reference case, delivery, atmospheric and aerodynamic uncertainties were based on state of the art navigation, current knowledge of Neptune atmosphere and computational fluid dynamics analyses respectively. Table 2 lists the uncertainties and distribution types used in the Monte Carlo reference case. In the first sensitivity case study, the magnitudes of the high frequency random density perturbations were reduced by $50 \%$. In the second sensitivity study, the latitudinal variation of Fminmax was removed and the uncertainty in mean density increased. In the third sensitivity study, alpha modulation was added to the reference bank modulation approach. The Monte Carlo analyses performed are summarized in Table 3. 
Table 2. Monte Carlo Uncertainties

\begin{tabular}{|c|c|c|c|c|}
\hline Category & Variable & Nominal & $\pm 3 \sigma$ or $\min / \max$ & Distribution \\
\hline \multicolumn{5}{|l|}{ Delivery State } \\
\hline & X position & 19813.3 km & From covariance & Correlated \\
\hline & Y position & $-16908.2 \mathrm{~km}$ & From covariance & Correlated \\
\hline & $\mathrm{Z}$ position & $2612.7 \mathrm{~km}$ & From covariance & Correlated \\
\hline & $X$ velocity & $-22.953 \mathrm{~km} / \mathrm{s}$ & From covariance & Correlated \\
\hline & Y velocity & $-13.324 \mathrm{~km} / \mathrm{s}$ & From covariance & Correlated \\
\hline & $\mathrm{Z}$ velocity & $11.316 \mathrm{~km} / \mathrm{s}$ & From covariance & Correlated \\
\hline \multicolumn{5}{|l|}{ Atmosphere } \\
\hline & Random Pertubation seed & 1 & 1 to 9999 & Uniform \\
\hline & Fbias & 0 & -0.56 to 0.56 & Uniform \\
\hline \multicolumn{5}{|l|}{ Aerodynamics } \\
\hline & Trim angle of attack & 40.0 & \pm 4.0 & Normal \\
\hline & $\mathrm{C}_{\mathrm{A}}$ & 0.349 & \pm 0.048 & Uniform \\
\hline & $\mathrm{C}_{\mathrm{N}}$ & 1.771 & \pm 0.120 & Uniform \\
\hline \multicolumn{5}{|l|}{ Mass Properties } \\
\hline & Axial C.G. (Xcg/L) & 0.51 & $\pm 0.50 \%$ & Uniform \\
\hline & Radial C.G. (Zcg/L) & -0.0166 & $\pm 0.125 \%$ & Uniform \\
\hline
\end{tabular}

Table 3. Summary of Monte Carlo Analyses

\begin{tabular}{lccc}
\hline \hline \multicolumn{1}{c}{ Case } & Perturbation Scale & Fminmax & Guidance \\
\hline Reference & 1.0 & f(latitude) & Bank angle modulation \\
Reduced Density Perturbations & 0.5 & f(latitude) & Bank angle modulation \\
Increased Density Uncertainty & 1.0 & global & Bank angle modulation \\
Alpha Modulation & 1.0 & f(latitude) & Bank + alpha modulation \\
\hline
\end{tabular}

\section{Results}

\section{A. Reference Case}

In the reference case, the reference set of uncertainties were used in the Monte Carlo analyses. Figure 8 shows the reference case atmospheric density variation in the aerocapture altitudes as a ratio of perturbed density to nominal density. The reference case density varies up to a factor of 2.25 .

The guidance compensates for these variations as well as delivery, aerodynamic, and C.G. variations by using the spacecraft's available control authority. Dispersions in apoapsis altitude at atmospheric exit result when the spacecraft's control authority is insufficient to compensate for the variations. Figure 9 shows the reference case dispersion in apoapsis and periapsis altitude and Fig. 10 shows a histogram of exit apoapsis altitude.

For the reference uncertainties, $100 \%$ of the cases successfully captured and $66.1 \%$ of the cases were within the desired science orbit apoapsis bounds. The dispersion in apoapsis altitude between the 0.13 percentile and 99.87 percentile was $461.4 \mathrm{E}+03 \mathrm{~km}$. The apoapsis percentiles are summarized in Table 4 .

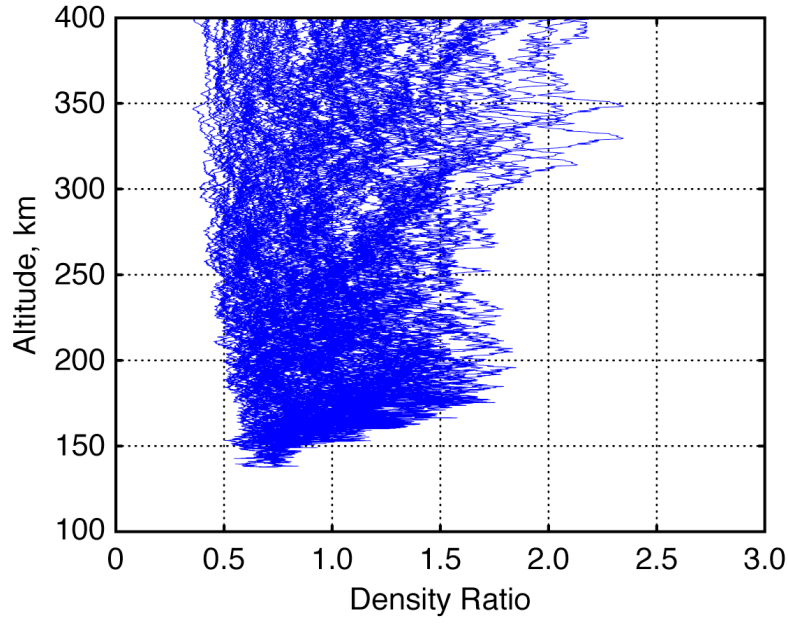

Figure 8. Reference Case Atmospheric Density Variation 
Table 4. Apoapsis Percentiles - Reference Case

\begin{tabular}{cc}
\hline \hline Apoapsis Statistics & Altitude, $\mathbf{x 1 0} \mathbf{3} \mathbf{~ k m}$ \\
\hline 0.13 percentile & 371.3 \\
50.00 percentile & 477.9 \\
99.87 percentile & 832.7 \\
\hline \hline
\end{tabular}

Impulsive maneuvers were used to adjust the atmospheric exit orbit to a nominal 3986 x $430000 \mathrm{~km}$ orbit. The 99.87 percentile $\Delta \mathrm{V}$ required to attain the nominal orbit and the percentage of cases captured were used as performance and robustness metrics. The 99.87 percentile $\Delta \mathrm{V}$ was used rather than a $3 \sigma$ value since the $\Delta \mathrm{V}$ distribution was skewed. The skewing is a result of $\Delta \mathrm{V}$ being required for periapsis raise in all cases regardless of whether or not the target apoapsis is met. Any error in apoapsis only results in increased $\Delta \mathrm{V}$. Table 5 summarizes these metrics for the reference case.

Table 5. Performance Metrics - Reference Case

\begin{tabular}{|c|c|}
\hline Robustness Statistics & $\%$ \\
\hline Cases Captured & 100 \\
\hline Cases within Target Bounds & 66.1 \\
\hline Performance Statistics & $\Delta \mathrm{V}, \mathbf{m} / \mathbf{s}$ \\
\hline 0.13 percentile & 88 \\
\hline 50.00 percentile & 141 \\
\hline 99.87 percentile & 360 \\
\hline
\end{tabular}

The system is sufficiently robust to overcome reference delivery, atmospheric and aerodynamic uncertainties. A 99.87 probability of attaining the science orbit is possible with a $360 \mathrm{~m} / \mathrm{s} \Delta \mathrm{V}$ budget for periapsis raise and apoapsis adjustment. The reference case $\Delta \mathrm{V}$ histogram is shown in Fig. 11.

\section{B. Reduced Atmospheric High Frequency Density Perturbations}

In the reduced high frequency density perturbation sensitivity study, the magnitude of atmospheric high frequency perturbations were reduced 50\% using the GRAM perturbation multiplier rpscale. The reduction may be possible with improved knowledge of Neptune's atmosphere. A half scale density perturbation near the periapsis of a selected aeropass is shown relative to full scale in Fig. 12. Note that a random perturbation is equally likely to be below the mean density as above it. Figure 13 shows the dispersion in apoapsis and periapsis altitude and Fig. 14 shows a histogram of exit apoapsis altitude.

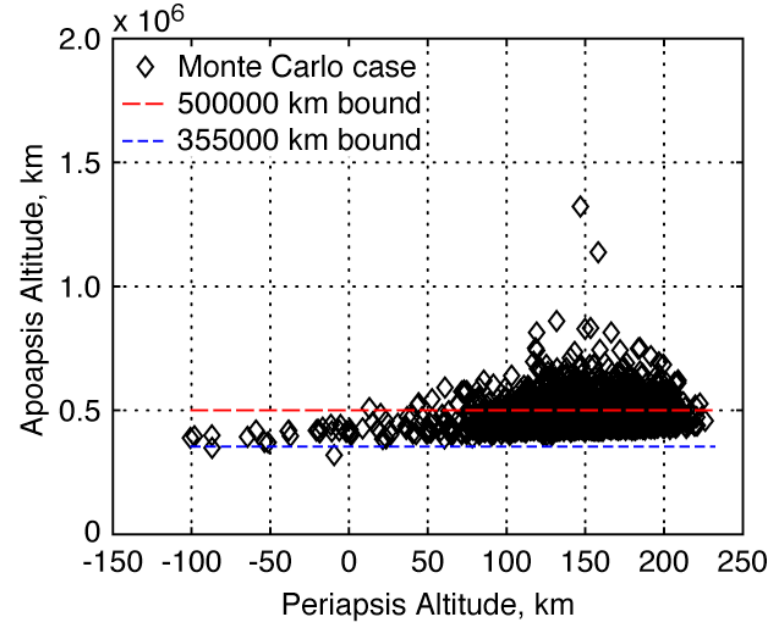

Figure 9. Apoapsis and Periapsis Altitude Dispersion - Reference Case

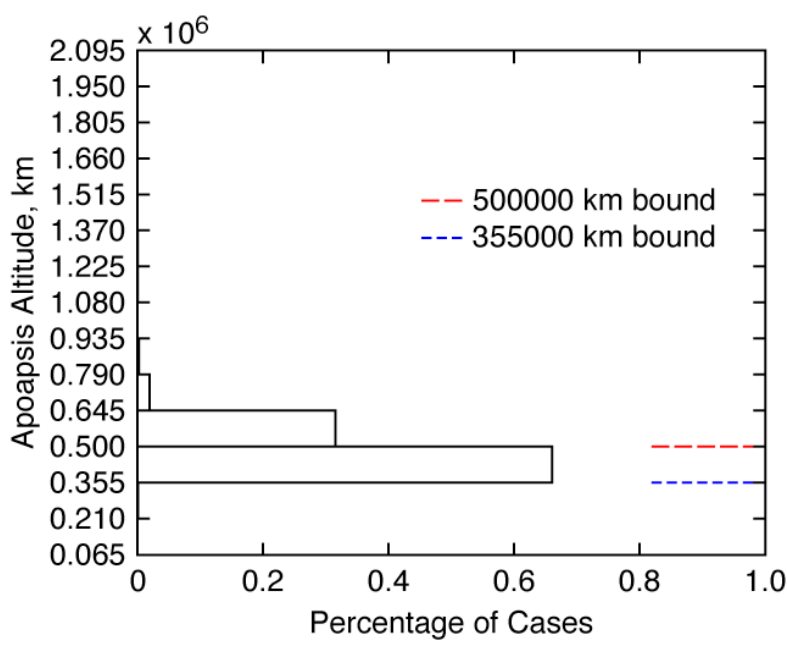

Figure 10. Apoapsis Altitude Histogram - Reference Case

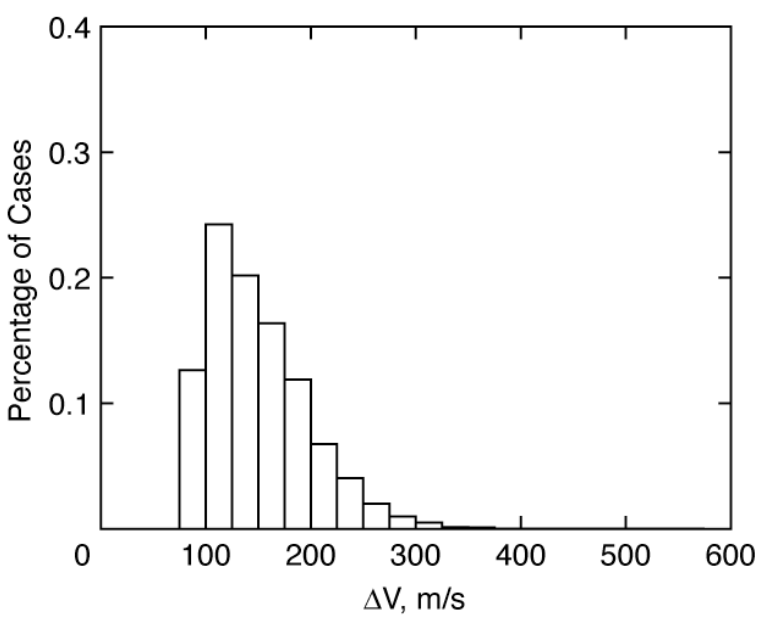

Figure 11. $\Delta$ V Histogram - Reference Case 


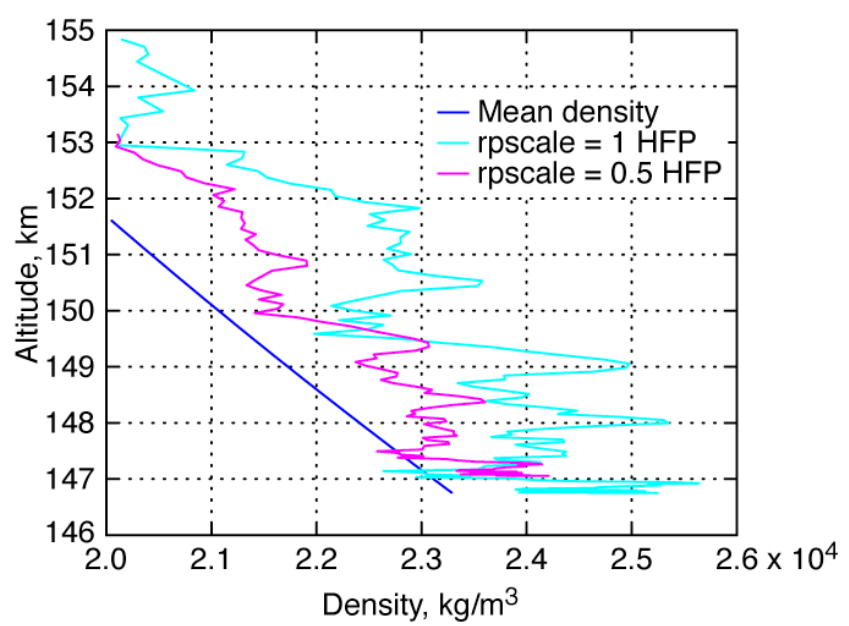

Figure 12. Comparison of Full and Half Scale High Frequency Density Perturbations

For an atmosphere with half scale high frequency density perturbations, $100 \%$ of the cases successfully captured and $81.8 \%$ of the cases were within the apoapsis bounds. In addition, the dispersion in apoapsis altitude was reduced $221.2 \mathrm{E}+03 \mathrm{~km}(47.9 \%)$ to $240.2 \mathrm{E}+03$ $\mathrm{km}$. The apoapsis percentiles are summarized in Table 6.

Table 6. Apoapsis Percentiles - Half Scale High Frequency Density Perturbations

\begin{tabular}{cc}
\hline \hline Apoapsis Statistics & Altitude, $\mathbf{x 1 0} \mathbf{~} \mathbf{~} \mathbf{~ m}^{\mathbf{3}}$ \\
\hline 0.13 percentile & 412.7 \\
50.00 percentile & 456.3 \\
99.87 percentile & 652.9 \\
\hline \hline
\end{tabular}

The performance statistics are summarized in Table 7. Reducing high frequency density perturbations $50 \%$ reduces 99.87 percentile $\Delta \mathrm{V}$ to $271 \mathrm{~m} / \mathrm{s}$, an $89 \mathrm{~m} / \mathrm{s}$ $(24.7 \%)$ reduction relative to the reference case. The smaller density perturbations can be compensated for with less control authority. This allows the guidance to improve targeting of the science orbit apoapsis and reduce $\Delta \mathrm{V}$ needed for apoapsis adjustment. The $\Delta \mathrm{V}$ histogram is shown in Fig. 15.

Table 7. Performance Metrics - Half Scale High Frequency Density Perturbations

\begin{tabular}{cc}
\hline \hline Robustness Statistics & $\mathbf{\%}$ \\
\hline Cases Captured & 100 \\
Cases within Target Bounds & 81.8 \\
\hline \hline Performance Statistics & $\Delta \mathbf{~ V , ~} \mathbf{~} / \mathbf{s}$ \\
\hline 0.13 percentile & 87 \\
50.00 percentile & 118 \\
99.87 percentile & 271 \\
\hline \hline
\end{tabular}

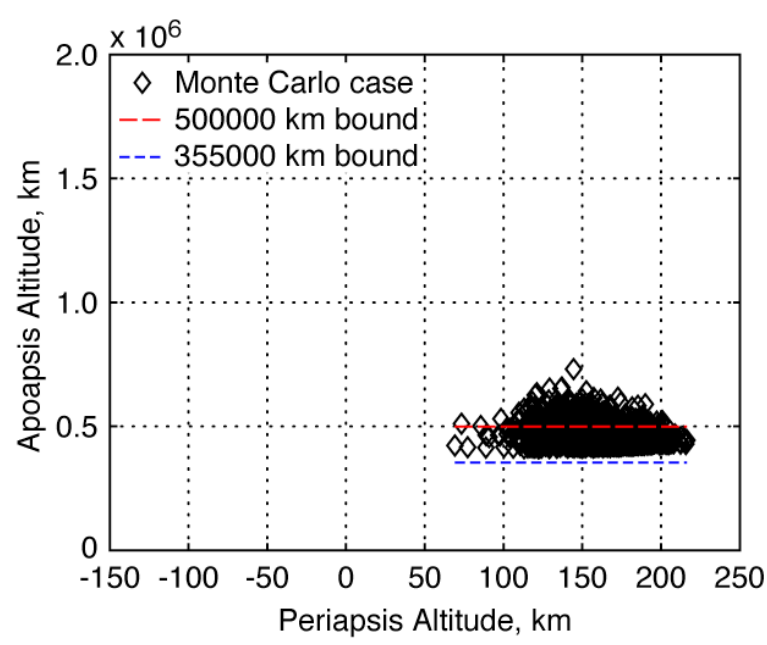

Figure 13. Apoapsis and Periapsis Altitude Dispersion - Half Scale High Frequency Density Perturbations

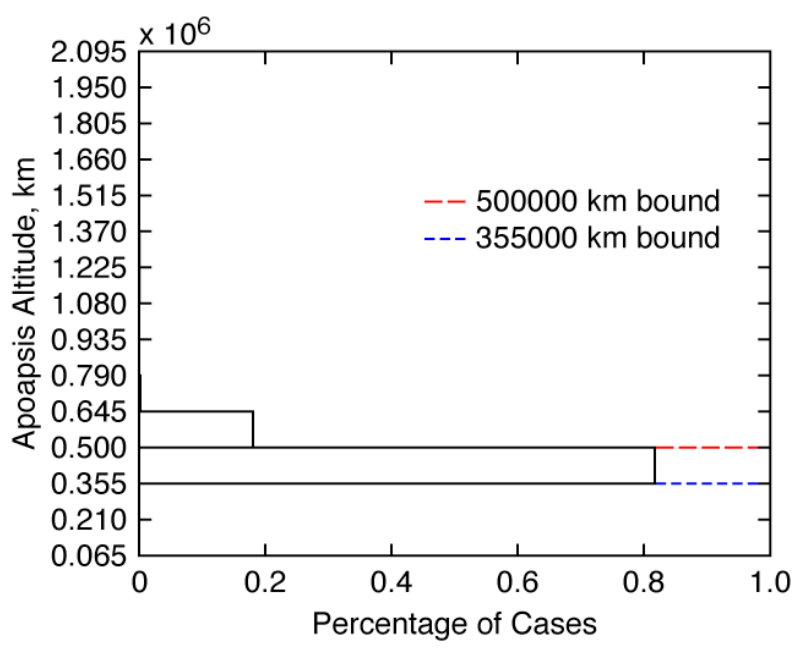

Figure 14. Apoapsis Altitude Histogram - Half Scale High Frequency Density Perturbations

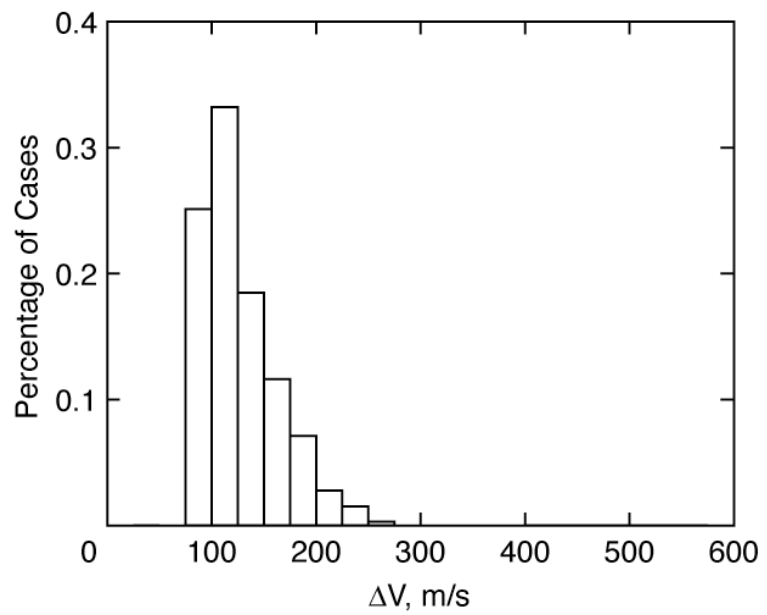

Figure 15. $\Delta$ V Histogram - Half Scale High FrquencyDensity Perturbations 


\section{Increased Mean Density Uncertainty}

In this sensitivity study, the latitudinal variation of Fminmax was removed. In addition, the Monte Carlo range of Fbias was increased from $-0.56 \leq$ Fbias $\leq 0.56$ to $-1 \leq$ Fbias $\leq+1$. This made Fminmax constant throughout a given aeropass and resulted in the largest possible uncertainty range of Fminmax, -1 to +1 . It also produces the maximum uncertainty in mean density from one aeropass to another. The maximum range of Fminmax is 33\% larger than the Fminmax range of the reference case. Figure 16 shows the density ratio in the aerocapture altitudes. In the altitude range of $125 \mathrm{~km}$ to 300 $\mathrm{km}$ where the majority of hyperbolic approach velocity is dissipated, the density variations above the nominal are approximately $25 \%$ larger than the reference atmosphere while density variations below the nominal are approximately $50 \%$ larger reductions.

The larger reduction in atmospheric density impacts the guidance's ability to target the apoapsis. For cases in which the density decreases, the spacecraft does not have the control authority to overcome the centripedal acceleration and descend into more dense atmospheric regions. As a result it exits with an apoapsis above the bounds. The dispersion in apoapsis and periapsis altitude is shown in Fig. 17. Figure 18 shows a histogram of exit apoapsis altitude.

For an atmosphere with increased uncertainties in mean density, $100 \%$ of the cases successfully captured and $76.3 \%$ of the cases were within the apoapsis bounds. The dispersion in apoapsis altitude increased 498.7E+03 $\mathrm{km}(108.1 \%)$ to $960.0 \mathrm{E}+03 \mathrm{~km}$. The apoapsis percentiles are summarized in Table 8.

Table 8. Apoapsis Altitude Percentiles - Increased Mean Density Uncertainty

\begin{tabular}{cc}
\hline \hline Apoapsis Statistics & Altitude, $\mathbf{x 1 0}^{\mathbf{3}} \mathbf{~ k m}$ \\
\hline 0.13 percentile & 324.9 \\
50.00 percentile & 448.7 \\
99.87 percentile & 1284.5 \\
\hline \hline
\end{tabular}

The system is robust enough to capture $100 \%$ of the cases with increased density uncertainty. However, the 99.87 percentile $\Delta \mathrm{V}$ increased $96.0 \mathrm{~m} / \mathrm{s}$ to $456 \mathrm{~m} / \mathrm{s}$, a $26.7 \%$ increase relative to the reference case. Table 9 summarizes the performance statistics. The $\Delta \mathrm{V}$ distribution is shown in Fig. 19.

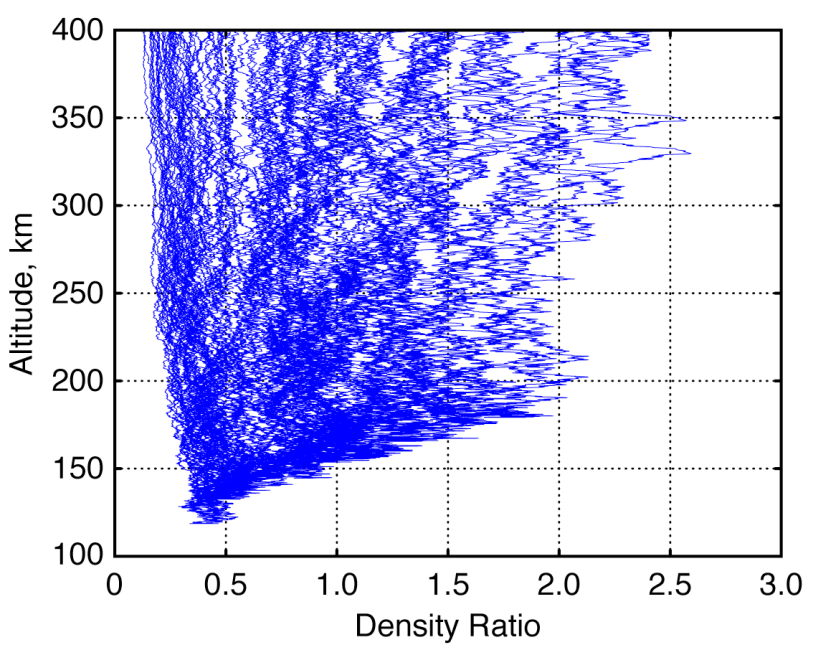

Figure 16. Atmospheric Density Variation for Maximum Range of Fminmax

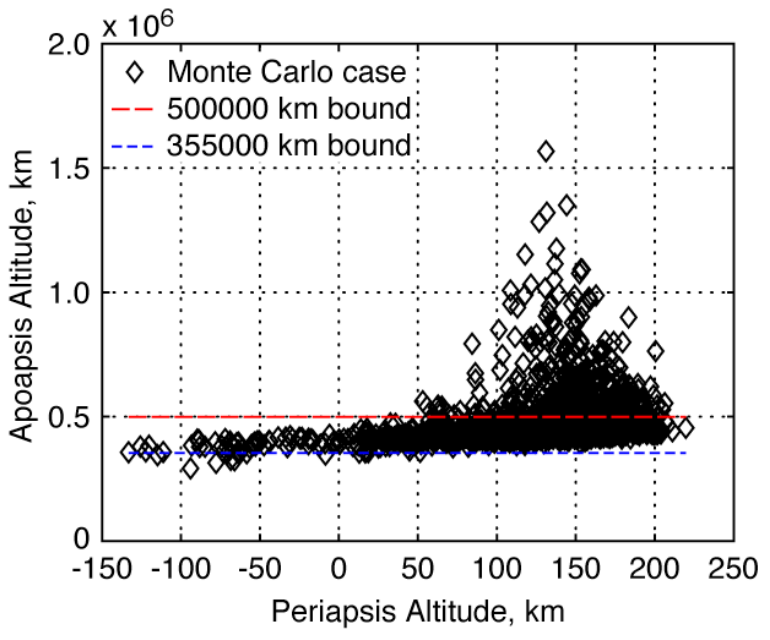

Figure 17. Apoapsis and Periapsis Altitude Dispersion - Increased Mean Density Uncertainty

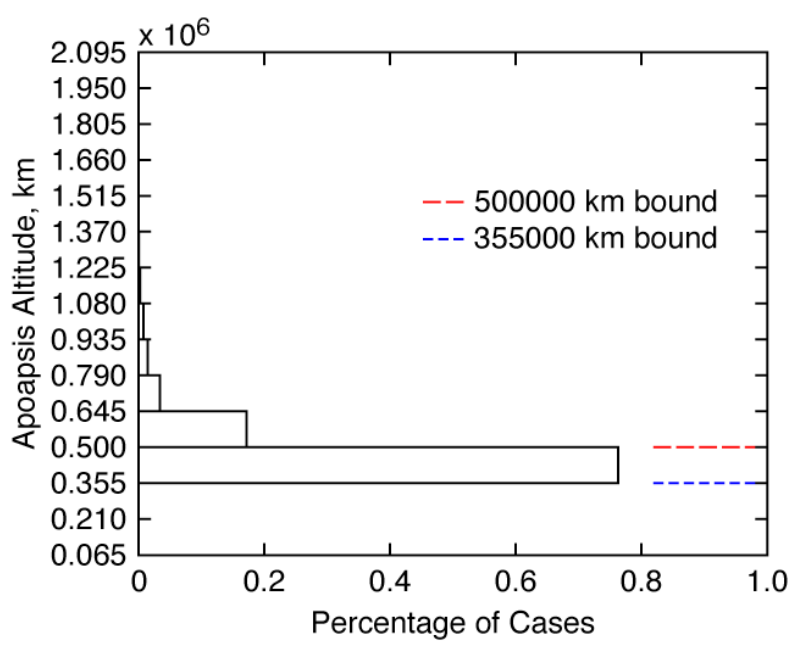

Figure 18. Apoapsis Altitude Histogram Increased Mean Density Uncertainty 
Table 9. Performance Metrics - Increased Mean Density Uncertainty

\begin{tabular}{cc}
\hline \hline Robustness Statistics & $\mathbf{\%}$ \\
\hline Cases Captured & 100 \\
Cases within Target Bounds & 76.3 \\
\hline \hline Performance Statistics & $\Delta \mathbf{~ V , ~} \mathbf{~} / \mathbf{s}$ \\
\hline 0.13 percentile & 88 \\
50.00 percentile & 125 \\
99.87 percentile & 456 \\
\hline \hline
\end{tabular}

\section{Alpha Modulated Guidance}

In the alpha modulated guidance sensitivity study, a guidance algorithm with angle of attack modulation in addition to bank modulation was used. The reference atmospheric uncertainty assumptions were used with the alpha modulated guidance case. The alpha modulated guidance improves the spacecraft's ability to compensate for density perturbations through changes in drag. Angle of attack modulation changes the drag more quickly than banking thus allowing the spacecraft to respond more quickly to density perturbations. The dispersion in apoapsis and periapsis altitude is shown in Fig. 20. Figure 21 shows a histogram of exit apoapsis altitude.

For a spacecraft with the alpha modulated guidance system, $100 \%$ of the cases were successfully captured and $98.4 \%$ of the cases were placed within the apoapsis bounds. The dispersion in apoapsis altitude decreased $335.5 \mathrm{E}+03 \mathrm{~km}(72.7 \%)$ to $125.9 \mathrm{E}+03 \mathrm{~km}$ relative to the reference case. The apoapsis percentiles are summarized in Table 10.

Table 10. Apoapsis Altitude Percentiles - Alpha Modulated Guidance

\begin{tabular}{cc}
\hline \hline Apoapsis Statistics & Altitude, $\mathbf{x 1 0} \mathbf{3}^{\mathbf{3}} \mathbf{k m}$ \\
\hline 0.13 percentile & 402.6 \\
50.00 percentile & 425.1 \\
99.87 percentile & 528.5 \\
\hline \hline
\end{tabular}

The alpha modulated guidance performance statistics are summarized in Table 11. The alpha modulated guidance reduced the 99.87 percentile $\Delta \mathrm{V}$ by $174.0 \mathrm{~m} / \mathrm{s}$ $(48.3 \%)$ to $186 \mathrm{~m} / \mathrm{s}$ relative to the reference case. The $\Delta \mathrm{V}$ histogram is shown in Fig. 22.

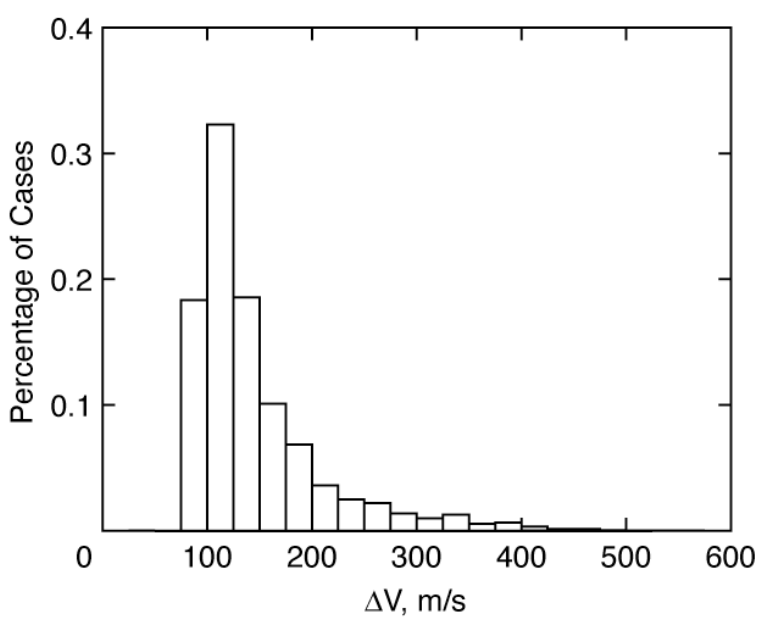

Figure 19. $\Delta$ V Histogram - Increased Mean Density Uncertainty

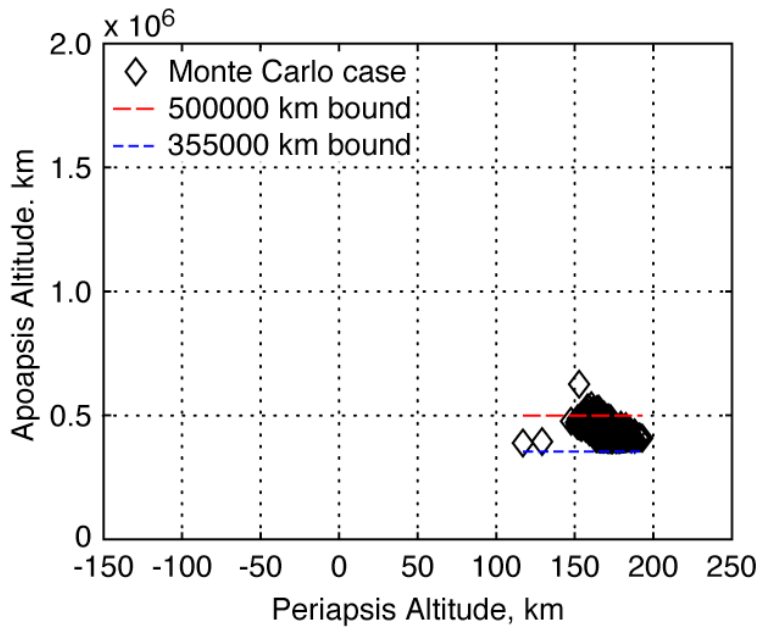

Figure 20. Apoapsis and Periapsis Altitude Dispersion - Alpha Modulated Guidance

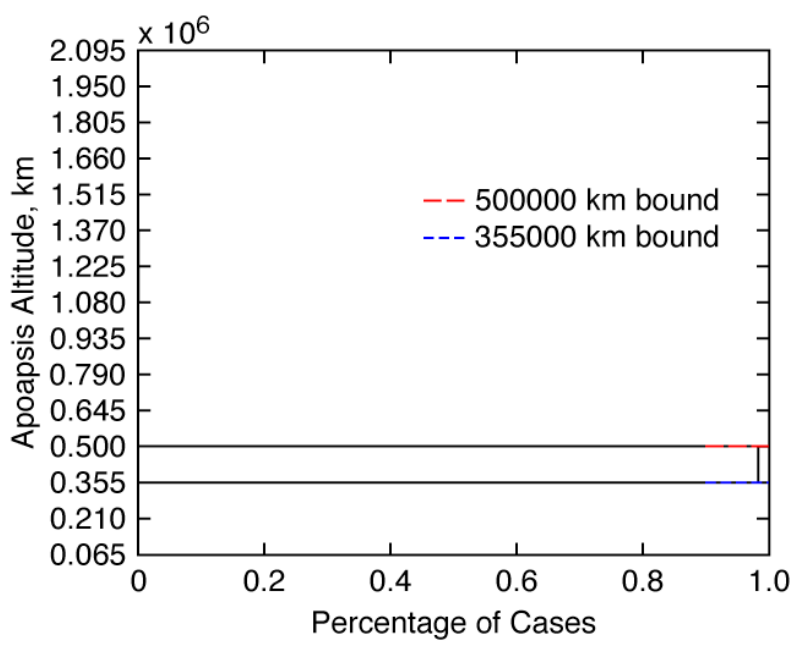

Figure 21. Apoapsis Altitude Histogram - Alpha Modulated Guidance 
Table 11. Performance Metrics - Alpha Modulated Guidance

\begin{tabular}{cc}
\hline \hline Robustness Statistics & $\mathbf{\%}$ \\
\hline Cases Captured & 100.0 \\
Cases within Target Bounds & 98.4 \\
\hline \hline Performance Statistics & $\Delta \mathbf{V}, \mathbf{~} / \mathbf{s}$ \\
\hline 0.13 percentile & 88 \\
50.00 percentile & 117 \\
99.87 percentile & 186 \\
\hline \hline
\end{tabular}

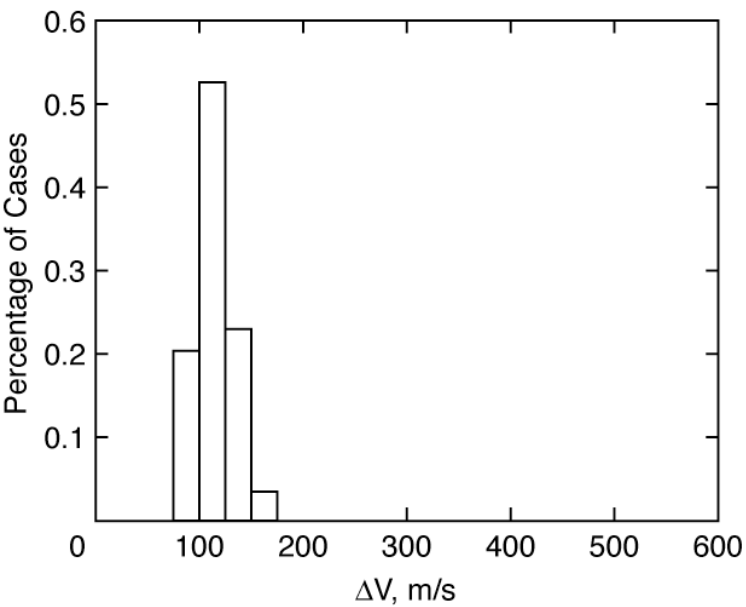

Figure 22. $\Delta$ V Histogram - Alpha Modulated Guidance

\section{Conclusion}

The performance analysis has shown that for the current Neptune atmospheric model, the $0.806 \mathrm{~L} / \mathrm{D}$ flatbottom ellipsled spacecraft is a viable design that captures $100 \%$ of the cases and has a 99.87 probability of successfully inserting the orbiter into its science orbit with a $360 \mathrm{~m} / \mathrm{s} \Delta \mathrm{V}$ budget for periapsis raise and apoapsis adjustment.

The analysis has also shown that the design is viable for atmospheric models with different variability assumptions. For an atmosphere with Fminmax uncertainties 33\% larger than that of the reference atmospheric model, the spacecraft can attain the science orbit with a 99.87 probability given a $456 \mathrm{~m} / \mathrm{s} \Delta \mathrm{V}$ budget for periapsis and apoapsis adjustment. If a better understanding of Neptune's atmosphere leads to a 50\% reduction in high frequency density perturbation magnitude, the science obit can be attained with a 99.87 probability given a $271 \mathrm{~m} / \mathrm{s} \Delta \mathrm{V}$ budget for periapsis and apoapsis adjustment. The analysis has also shown that with a combined angle of attack and bank angle modulation the spacecraft can attain the science orbit with a 99.87 probability given a $186 \mathrm{~m} / \mathrm{s} \Delta \mathrm{V}$ budget for periapsis and apoapsis adjustment.

\section{References}

${ }^{1}$ Lockwood, M. K., "Neptune Aerocapture Systems Analysis,” AIAA-2004-4951, Conference proceedings of the AIAA Atmospheric Flight Mechanics Conference and Exhibit, Providence, Rhode Island, August 2004.

${ }^{2}$ Spilker, Tom, "Significant Scienceat Titan and Neptune," EGU04-A-2270, Conference Proceedings of European Geosciences Union Planetary and Solar Sciences Programme, Nice, France, April 2004

${ }^{3}$ Noca, Muriel, Bailey, R. W., "Mission Trades for Aerocapture at Neptune," AIAA-2004-3843, Conference Proceedings of the $40^{\text {th }}$ AIAA/ASME/SAE/ASEE Joint Propulsion Conference and Exhibit, Huntsville, AL, July 2004

${ }^{4}$ Bailey, R. W., Hall, J. L., Spilker, T. R., Okong'o, N. O., "Neptune Aerocapture Mission and Spacecraft Design Overview" AIAA-2004-3842, Conference Proceedings of the $40^{\text {th }}$ AIAA/ASME/SAE/ASEE Joint Propulsion Conference and Exhibit, Huntsville, AL, July 2004

${ }^{5}$ Hanak, C., Bishop R., “Aerocapture Navigation Analysis at Titan and Neptune,” AIAA-2004-5180, Conference Proceedings of the AIAA Atmospheric Flight Mechanics Conference and Exhibit, Providence, Rhode Island, August 2004

${ }^{6}$ Justus, C. G., Duvall, A., Keller, V., “Atmospheric Models for Aerocapture Systems Studies,” AIAA-2004-4952, Conference Proceedings of the AIAA Atmospheric Flight Mechanics Conference and Exhibit, Providence, Rhode Island, August 2004

${ }^{7}$ Edquist, K. T., Hoffman, D. A., Rea, J.R., "Configuration, Aerodynamics and Stability Analysis for a Neptune Aerocapture Orbiter," AIAA-2004-4953, Conference Proceedings of the AIAA Atmospheric Flight Mechanics Conference and Exhibit, Providence, Rhode Island, August 2004

${ }^{8}$ Masciarelli, J. P., Westhelle, C. H., Graves, C. A., "Aerocapture Guidance Performance for the Neptune Orbiter," AIAA2004-4954, Conference Proceedings of the AIAA Atmospheric Flight Mechanics Conference and Exhibit, Providence, Rhode Island, August 2004

9Bauer, G. L., Cornick, D. E., Olson, D. W., Petersen, F. M., Stevenson, R., "Program to Optimize Simulated Trajectories (POST II)," NASA CR-2770, February 1977 